\title{
Should Fiscal Policy Be Different in a Non-Competitive Framework?
}

\author{
Arantza Gorostiaga \\ CEMFI \\ Working Paper No. 9901 \\ January 1999
}

I would like to thank Albert Marcet for his helpful suggestions and guidance. I have also benefited from discussions with Manuel Balmaseda, Samuel Bentolila, Lawrence Christiano, Martin Eichenbaum, Larry Jones, Christopher Phelan and Thomas Sargent. I am also indebted to Jorge Blázquez, J. Ignacio García, J.F. Rubio and seminar audiences at CEMFI, Universidad del País Vasco, FEDEA, Northwestern University, III Workshop on Dynamic Macroeconomics and IXth Summer School of the EEA for useful comments. Finally, thanks to Stuart Gurrea, Dan Levy, Nuno Martins, Ernesto Villanueva, and SIAE for invaluable encouragement and suggestions. All remaining errors are my own. (E-mail: arantza@cemfi.es).

CEMFI, Casado del Alisal 5, 28014 Madrid, Spain.

Tel: 341 4290551, fax: 341 4291056, www.cemfi.es. 


\begin{abstract}
This paper aims to study if imperfections in the labor market justify a fiscal policy where public spending, labor income tax rates and debt are set to stabilize output. We present a dynamic general equilibrium model and solve for the optimal policy considering two different labor market setups. First we assume a competitive labor market and then we introduce a union with monopoly power in the labor market. Both models reach the same conclusion as regards the stabilization policy: it is not optimal to use the fiscal policy to stabilize. We also find that government spending should be larger when a competitive labor market is assumed. These main results arise both under complete and incomplete markets for the debt.
\end{abstract}




\section{Introduction}

The purpose of this paper is to study how the optimal fiscal policy changes when we introduce some rigidity in a competitive framework. When we talk about imperfections in the model we are thinking about lack of competition in the labor market. We are specially interested in analyzing the way this optimal policy moves over the business cycle. We would like to address questions that have traditionally been a concern of macroeconomists, for example: Should the government apply stabilization policies? ${ }^{1}$ Should fiscal policy be different when a non-competitive labor market is assumed?

This kind of questions were answered in the past using the IS-LM model. The IS-LM model has been one of the most popular frameworks used by economists to derive economic policy recommendations. As King (1993) points out, there are researchers" ${ }^{2} 3$ who think that "the IS-LM model is the best way to understand the determinants of aggregate demand and to conduct contemporary policy analysis". These authors think that, probably, it is not worth writing more complex models because the resulting optimal policy is the same in any case. Nevertheless, the IS-LM does not seem to be an appropriate setup for research. Some weaknesses of the model are that it is a static model with agents not optimizing or that the government is not

\footnotetext{
${ }^{1}$ We will say that the government uses stabilization fiscal policy when public expenditures are negatively correlated with output and when the correlation between tax rates and output is positive.

2 "The textbook IS-LM model, augmented by the Phillips curve, continues to provide the best way to interpret discussions of economic policy in the press and among policy makers". Mankiw (1990).

3 "Right or wrong, the IS-LM model, and its intellectual cousins, the Mundell-Fleming model and the various incarnations of aggregate supply-aggregate demand models, have proved incredibly useful at analyzing fluctuations and the effects of policy". Blanchard (1997).
} 
aware of its budget constraint.

We aim to use a different approach to analyze these questions. Public finance literature has applied Ramsey's formulation to analyze fiscal policy over time. Barro (1979) develops a theory of optimal public finance in a deterministic model. Kydland and Prescott (1980) examine the problem of optimal policy selection within the rational expectations competitive framework. Lucas and Stokey (1983) consider a stochastic economy without capital and study the structure and time-consistency of optimal fiscal and monetary policy. There has been a number of articles which have analyzed optimal fiscal taxation in an extended Lucas and Stokey's environment. For example, Zhu (1992) considers an economy with capital accumulation and Marcet, Sargent and Seppälä (1996) only allow for risk-free debt.

We want to analyze how the optimal fiscal policy moves over the cycle under different labor market setups. More precisely, we are interested in studying how the following three variables evolve: government expenditure, tax rates and debt issues. This requires a government taking decisions about its spending, that is, an endogenous government expenditure. Thus, we are going to assume that the government chooses the level of public spending and that consumers derive utility from it. All the models we have mentioned above assume that government expenditure plays no specific role in the economy and is taken as exogenously given by all the agents. Jones, Manuelli and Rossi (1993) and Rojas (1993) study the Ramsey optimal policy including government spending as a productive input in the model. The first paper aims to analyze how growth and welfare change when there is a switch to the optimal policy. Rojas (1993) is interested in the cyclical properties of the 
optimal policy. His model does not allow for the possibility of issuing debt and labor is inelastically supplied. He predicts a procyclical public policy in the sense that both public investment and capital income taxes are positively correlated with output.

We also depart from Lucas and Stokey (1983) in that we introduce rigidities in the labor market. Lucas and Stokey assume a linear technology which yields an inelastic labor demand, that is, the inverse labor demand does not depend on the labor allocation. If we considered such a production function, the union would not have any chance to set wages and both the competitive model and the non-competitive one would yield the same results. That is why we assume a non-linear production function which implies a flexible demand schedule.

We present a dynamic model with agents living forever. In our economy there is a representative consumer, a firm and a government and all of them take decisions optimally. We introduce two different assumptions with respect to wage setting: first, we assume that both the firm and the worker are price takers and then, we consider the case in which there is a union with an effective monopoly in the labor market. The government provides a public good and finances its expenditures with labor income taxes and debt. First, we will analyze the case in which debt is state contingent and complete markets are assumed. And then we will study if the results change when only risk free debt is allowed. Although the second case seems much more interesting, the complete markets assumption makes equilibria easier to compute and interpret. The government is assumed to be a Ramsey planner who decides the optimal fiscal policy maximizing the consumer's utility. 
We compute the full-commitment solution. If the government could reoptimize in the future, it would do something different from what it had promised to do and the solution would be time-inconsistent.

The computational issues associated with the finding of the equilibrium stochastic processes are a crucial element of our work. Due to the assumptions made and the model formulation itself, closed form solutions are not available and we have to use computer simulations.

The two models analyzed deliver the same conclusion with respect to the stabilization policy: it is not optimal to use the fiscal policy to offset the negative effects of the cycle.

We also find that, due to the additional distortion introduced in the labor market, the optimal public spending is lower in the model considering a union than in the competitive one. The resulting government expenditure is smaller both in its level and as a proportion of the output of the economy. These conclusions go against the conventional belief that rigidities lead to more active public policies and a large role for government intervention. In contrast with traditional analyses, our model does not suggest that an active stabilization policy should be carried out when a non-competitive labor market is assumed.

The paper is organized as follows. In section 2 we assume that the government can issue state contingent debt; we set the basic theoretical framework and consider two models, the competitive one in which both the worker and the firm are price takers in the labor market, and the non-competitive model in which we assume that there is a union which sets wages; and we analyze the results using numerical simulations. Section 3 performs the same exercise 
but assuming that only risk-free debt is available to the government. Finally, section 4 concludes.

\section{The model with state contingent debt}

\subsection{The basic setup}

We consider a production economy with three infinitely-lived agents: a representative consumer, a firm, and the government. There is a private consumption good $\left(c_{t}\right)$ and a public good $\left(g_{t}\right)$ that satisfy

$$
c_{t}+g_{t}=y_{t}
$$

where $y_{t}$ is the aggregate production.

In Lucas and Stokey (1983) a linear production function is assumed. This implies that the demand for labor is inelastic. In this paper we are interested in studying the fiscal policy in different labor market setups assuming different degrees of rigidity in this market. In order for the non-perfect labor market to make sense, a non-rigid labor demand is required. We can obtain this by assuming a technology showing decreasing returns to labor input. We consider a constant returns to scale concave production function:

$$
y_{t}=f\left(\mu_{t} ; 1 ; x_{t} ;{ }_{t}\right)
$$

where $\mathbf{X}_{\mathrm{t}}$ denotes leisure, ' $\mathrm{t}$ is land and $\mu_{\mathrm{t}}$ is a productivity shock following a Markov process:

$$
\ln \mu_{t}=1 / 2 n \mu_{t_{i} 1}+{ }^{\prime} ; \quad j 1 / 3<1 ; \quad{ }_{t} \gg N(0 ; 3 / 4)
$$


This technology shock is the only source of uncertainty in our economy.

The study of stabilizing public expenditure policies requires a model with endogenous government spending. We have endogenized this variable assuming that there is a new consumption good provided as government services. The consumer derives utility from private consumption, public spending and leisure. The household's preferences are given by the von NeumannMorgenstern utility function:

$$
\mathrm{E}_{0}{ }_{\mathrm{t}=0}^{X^{\mathrm{N}}}-\mathrm{t} \mathrm{u}\left(\mathrm{c}_{\mathrm{t}} ; \mathrm{g}_{\mathrm{t}} ; \mathrm{x}_{\mathrm{t}}\right) ; \quad 0<^{-}<1
$$

The utility function $u$ is strictly increasing in the three arguments and strictly concave. Private consumption, government expenditures and leisure are normal (non-inferior). $E_{0}$ denotes the mathematical expectation conditioned on time 0 information.

The representative consumer is endowed with one unit of time which is devoted to work and leisure. He also owns ${ }^{\top}$ units of land that will be inelastically supplied to the firm. Besides, the household can lend to or borrow from the government with a full array of contingent one-period bonds that complete the markets. The consumer faces the following budget constraint:

$$
c_{t}+p_{t}^{b}(\mu) b_{t}(\mu) d \mu=\left(1 ; \quad i_{t}\right) w_{t}\left(1 ; \quad x_{t}\right)+b_{t_{i} 1}\left(\mu_{t}\right)+p_{t}^{\prime} t_{t}
$$

where $i_{t}$ is the income tax, $w_{t}$ the wage rate and $p_{t}$ is the land price. On the other hand, $\mathrm{p}_{\mathrm{t}}^{\mathrm{b}}(\mu)$ denotes the price the consumer has to pay in period t to get one unit of consumption good at $t+1$ if the productivity shock realization is $\mu$ at this time and $b_{t}(\mu)$ is the number of units of debt (contingent on $\mu$ ) held in period t. We assume that the consumer is a price taker in the goods 
market, in the land market and in the contingent claims market. However, we are going to consider two different kinds of behavior for the consumer in the labor market. First, we assume that the worker is a price taker in the labor market. And second, we consider that the worker gives his labor to a union which has monopoly power in the labor market and which sells labor to the firm. In this case the union sets the wage and the labor allocation is that resulting from the firm's labor demand. The household's problem is to choose $f c_{t} ; b_{t} ; x_{t} ;{ }^{t} g$ maximizing the discounted sum of utilities given by (4) subject to the temporal sequence of budget constraints (5) and taking $\left\{i_{t} ; g_{t} ; b_{i} 1 ; \mu_{t} ; p_{t}^{b} ; p_{t}\right\}$ as given. ${ }^{4}$ The first order conditions require that:

$$
p_{t}^{b}(\mu)=-\frac{u_{c ; t+1}(\mu)}{u_{c ; t}} \operatorname{Pr}\left(\mu_{t+1}=\mu n \mu_{t}\right)
$$

where $u_{c t}$ is the marginal utility of consumption at $t$. The consumer supplies inelastically the land he owns. The derivative with respect to leisure will be considered later.

The firm is supposed to be a price-taker in all markets. It produces the consumption good using land and labor as inputs. The firm seeks to maximize its profits,

$$
1 / 4=y_{t} ; \quad w_{t}\left(1 ; x_{t}\right) ; \quad p_{t}^{\prime}
$$

where $f w_{t} ; p_{t} g$ are given to the firm. The solution to the problem of the firm implies that inputs inverse demands equal the corresponding marginal productivity, that is,

\footnotetext{
${ }^{4}$ In the competitive model, the consumer is also a price taker in the labor market. In the non-competitive case, the firm's labor demand is an additional constraint in the household's problem.
} 


$$
\begin{array}{ll}
w_{t}(\phi, & f_{1_{i} x}\left(\mu_{t} ; \phi_{t}{ }_{t}\right) \\
p_{t}(\phi) & f \cdot\left(\mu_{t} ; 1 ; x_{t} ;:\right)
\end{array}
$$

where $f_{1_{i}}$ and $f$ - are the derivatives of the production function with respect to labor and land respectively.

Finally, the government provides the public consumption good and finances its expenditures by labor income taxes and public debt. The government budget constraint is the following:

$$
g_{t}+b_{t_{i} 1}\left(\mu_{t}\right)=i_{t} w_{t}\left(1 ; \quad x_{t}\right)+{ }^{Z} p_{t}^{b}(\mu) b_{t}(\mu) d \mu
$$

In our setup, the government is assumed to be a benevolent social planner whose objective is to choose a fiscal policy in order to maximize the welfare of the economy. The government is aware of the household's answer to his policy announcements and takes this reaction into account when it solves its maximization problem. This application of optimal taxation theory is known as the Ramsey problem in the literature. ${ }^{5}$ In other words, the social planner faces the following restrictions: the temporal sequence of budget constraints (8), the feasibility constraint (1) and the first order conditions resulting from the programs solved by the other agents in the economy. Using standard arguments, we can prove ${ }^{6}$ that the restriction that (6) and (8) place

\footnotetext{
${ }^{5}$ Basically, our model presents a Stackelberg game. Here, the government (the Stackelberg leader) chooses the fiscal policy first and the consumer (the follower) observes this decision before choosing his consumption and leisure allocations. To find the equilibrium, we are using the backward induction procedure.

${ }^{6} \mathrm{~A}$ formal proposition and proof showing this result can be found in Chari and Kehoe (1998).
} 
on Ramsey equilibrium allocations is characterized by the implementability constraint: $:^{7} ;$

$$
\mathrm{b}_{\mathrm{i} 1}=\mathrm{E}_{0}{ }_{\mathrm{t}=0}^{\mathrm{X}}-\frac{\mathrm{t}}{\mathrm{u}_{\mathrm{c} ; \mathrm{t}}}\left[\mathrm{u}_{\mathrm{c} ; \mathrm{t}} \mathrm{w}_{\mathrm{t}}\left(1 ; \mathrm{x}_{\mathrm{t}}\right) ; \mathrm{g}_{\mathrm{t}}\right]
$$

That is, the present value of outstanding government obligations at time 0 must equal the present value of the excesses of tax revenues over government expenditures on goods.

\subsection{The competitive model}

In this subsection we describe the competitive model. We assume that both the consumer and the firm are price-takers in the goods and in the inputs markets.

When the consumer takes the wage as given, the labor supply and the consumption good demand are determined from equation (6) and the following additional equation:

$$
\left(1 ; \quad i_{t}\right) w_{t}=\frac{u_{x ; t}}{u_{c ; t}}
$$

where $\mathrm{u}_{\mathrm{ct}}$ and $\mathrm{u}_{\mathrm{xt}}$ are the marginal utility of consumption and leisure respectively.

\footnotetext{
${ }^{7}$ We assume that there are high enough debt limits to prevent the possibility of a Ponzi game. As a result, the following transversality constraint is fulfilled:

$$
\lim _{T ! 1} E_{t}{ }^{-T+1} \frac{u_{c ; T+1}}{u_{c ; 0}} b_{T+1}{ }^{\lrcorner}=0
$$

${ }^{8}$ We can prove this result because of the complete market assumption which permits the government to sell bonds contingent on every possible realization of the productivity shock $\mu$.
} 
In our analysis, it is going to be useful to define the competitive equilibrium allocations as follows:

Definition 1: Given $b_{i} 1$ and the productivity shock process $f \mu_{t} g$, a competitive equilibrium is a stochastic process of prices $f p_{t}^{b}(\mu) ; w_{t} ; p_{t} g$, allocations $f c_{t} ; b_{t} ; x_{t} ;{ }_{t} g$ and fiscal policy $f g_{t} ; i_{t} ; b_{t} g$ such that:

i) $f c_{t} ; b_{t} ; x_{t}$; ${ }^{t} g$ maximizes the consumer's objective function (4) subject to the budget constraints $(5)$ given $f p_{t}^{b}(\mu) ; w_{t} ; p_{t} g$ and $f g_{t} ; i_{t} g$.

ii) $f x_{t} ;{ }^{\prime} g$ maximizes the firm's profits $(7)$ given $f w_{t} ; p_{t} g$.

iii) The government budget constraint (8) and the economy's technology constraint (1) are satisfied at each period.

iv) The labor, land, consumption goods and bonds markets clear.

As has been pointed out in the preceding subsection, the Ramsey problem consists of maximizing the objective function (4) over the competitive equilibria defined above. Equations (9) and (10) allow us to write the Ramsey problem as follows,

$$
\max _{f g_{t} ; i t ; b_{t} g} E_{0}{ }_{t=0}-t u\left(c_{t} ; g_{t} ; x_{t}\right)
$$

subject to:

$$
\begin{aligned}
\mathrm{b}_{\mathrm{i} 1} \mathrm{u}_{\mathrm{c} ; 0} & =\mathrm{E}_{0}^{\mathrm{X}^{\lambda}}{ }_{\mathrm{t}=0}^{-\mathrm{t}}\left[\mathrm{u}_{\mathrm{c} ; \mathrm{t}}\left(\mathrm{w}_{\mathrm{t}}\left(1 ; \mathrm{x}_{\mathrm{t}}\right) \mathrm{i} \mathrm{g}_{\mathrm{t}}\right) \mathrm{i} \mathrm{u}_{\mathrm{x} ; \mathrm{t}}\left(1 ; \mathrm{x}_{\mathrm{t}}\right)\right] \\
\mathrm{c}_{\mathrm{t}}+\mathrm{g}_{\mathrm{t}} & =\mathrm{f}\left(\mu_{\mathrm{t}} ; 1 ; \mathrm{x}_{\mathrm{t}} ;^{\top}\right) \\
\mathrm{w}_{\mathrm{t}} & =\mathrm{f}_{1_{\mathrm{i}} \mathrm{x}}\left(\mu_{\mathrm{t}} ; 1 ; \mathrm{x}_{\mathrm{t}} ;^{\top}\right)
\end{aligned}
$$




\section{$\mathrm{f} \mu_{\mathrm{t}} \mathrm{g}, \mathrm{b}_{\mathrm{i}} \mathrm{a}$ as given}

The Lagragian for this problem is:

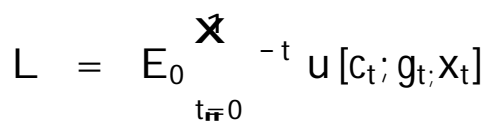

$$
\begin{aligned}
& +, b_{i 1} u_{c ; 0} i E_{0}^{X^{A}}{ }_{t=0}^{-t}\left[u_{c ; t}\left(w_{t}\left(1 ; x_{t}\right) ; g_{t}\right) ; u_{x ; t}\left(1 ; x_{t}\right)\right]
\end{aligned}
$$

where, is the Lagrange multiplier associated with the implementability constraint.

The first order conditions of this problem are: ${ }^{9}$

$$
\begin{array}{r}
\mathrm{i} u_{c ; t} f_{1_{i} x ; t}+u_{x ; t}+{ }^{-}{ }_{1 t}=0 \\
i u_{c ; t}+u_{g ; t}+{ }_{-2} t=0
\end{array}
$$

where

$$
\begin{aligned}
-{ }_{1 t}= & u_{c c ; t} f_{1_{i} x ; t}\left[f_{1_{i} x ; t}\left(1 ; x_{t}\right) ; g_{t}\right] ; u_{c ; t} f_{1_{i} x 1_{i} x ; t}\left(1 ; x_{t}\right) \\
& +u_{c ; t} f_{1_{i} x ; t}+u_{x x ; t}\left(1 ; x_{t}\right) ; u_{x ; t} \\
-{ }_{2 t}= & u_{c ; t}+\left(u_{c c ; t} ; u_{c g ; t}\right)\left[\begin{array}{lll}
f_{1 i x ; t}(1 ; & \left.x_{t}\right) ; & g_{t}
\end{array}\right]
\end{aligned}
$$

If an optimal policy exists and the solution is interior, the optimal allocations must satisfy (11), (12), the resource constraint (1) and the implementability constraint (9). These first order conditions can be written as

\footnotetext{
${ }^{9}$ If we consider $b_{1}{ }_{1} \in 0$ the first order conditions are slightly different in period 0 .
} 
equations of the form $\mathrm{F}\left(\mathrm{z}_{\mathrm{t}} ; \mu_{\mathrm{t}} ;,\right)=0$ where $\mathrm{z}_{\mathrm{t}}$ is a vector of endogenous variables. Hence, we can conclude that the optimal fiscal policy only depends on the contemporaneous productivity shock $\mu_{\mathrm{t}}$ and the Lagrange multiplier, , and it has the same correlation properties as the former. ${ }^{10}$ We can represent the endogenous variables by a time-invariant function of $\mu_{\mathrm{t}}$ and ,

$$
\left(c_{t} ; x_{t} ; g_{t} ; i_{t} ; p_{t} ; b_{t}\right)=d^{C}\left(, ; \mu_{t}\right)
$$

\subsection{The non-competitive model}

As we have pointed out before, this paper's goal is to analyze how the optimal fiscal policy changes when we introduce some imperfection in a neoclassical framework. We introduce these rigidities in the labor market assuming that there is a union which has an effective monopoly on the sale of labor to the firm. It is assumed that the worker gives his labor to the union and it is the union who deals with the firm. The firm has a downward-sloping labordemand curve which specifies how much labor it is willing to hire at any wage. In our model this labor-demand curve is a constraint on union behavior. The union is going to maximize the objective function (4) subject to the sequence of budget constraints and taking $f_{i_{t}} ; g_{t} ; b_{i} ; ; \mu_{t} ; p_{t}^{b} g$ and $w_{t}(\varnothing$ as given. In this case, the union takes into account that the wage the worker is going to get depends on his own labor decisions. As a result, the consumer's problem first order conditions are (6) and the following equation:

$$
\left(1 ; \quad i_{t}\right)\left[w _ { t } \left(\phi+w_{t}^{0}\left(\phi\left(1 ; \quad x_{t}\right)\right]=\frac{u_{x ; t}}{u_{c ; t}}\right.\right.
$$

We can rewrite this expression as follows:

\footnotetext{
${ }^{10}$ This result is analogous to that found in Lucas and Stokey (1983).
} 


$$
\left(1 ; \quad i_{t}\right) w_{t}=\frac{u_{x ; t}}{u_{c ; t}}\left(1+m_{t}\right)
$$

where $m_{t}$ is the positive mark-up the union gets due to the monopoly power it has in the labor market. ${ }^{11}$ This equation shows that the marginal rate of substitution between leisure and consumption is not equal to the marginal rate of transformation, not only because of the labor income tax rate but also because of this mark-up. Another conclusion we can draw from this expression, for any allocation $f c_{t} ; g_{t} ; x_{t} g$ the labor income tax rate is higher in the neoclassical model.

The following definition characterize the equilibrium with imperfect competition allocations over which the government maximizes its objective function:

Definition 2: Given $b_{i}$ and the productivity shock process $f \mu_{t} g$, an equilibrium with imperfect competition is a stochastic process of prices $f p_{t}^{b}(\mu) ; w_{t} ; p_{t} g$, allocations $f_{c_{t}} ; b_{t} ; x_{t} ;{ }^{t} g$ and fiscal policy $f g_{t} ; \iota_{t} ; b_{t} g$ such that:

i) $f c_{t} ; b_{t} ; x_{t} ;{ }^{t} g$ maximizes the consumer's objective function (4) subject to the budget constraints $(5)$ given $f p_{t}^{b}(\mu) ; p_{t} g$ and $f g_{t} ; i_{t} g$ and the firm's labor-demand curve $\mathrm{w}_{\mathrm{t}}(\emptyset$.

ii) $f x_{t} ;{ }^{t} g$ maximizes the firm's profits $(7)$ given $f w_{t} ; p_{t} g$.

${ }^{11} \mathrm{~m}_{\mathrm{t}}$ is defined by

$$
1+m_{t}=\frac{w_{t}(\phi)}{w_{t}\left(\phi+w_{t}^{0}\left(\phi\left(1 ; x_{t}\right)\right.\right.}
$$

This mark-up is positive by the concavity of the production function. 
iii) The government budget constraint (8) and the economy's technology constraint (1) are satisfied at each period.

iv) The labor, land, consumption goods and bonds markets clear.

Substituting (13) in (9), we can write the Lagrangian for the Ramsey problem as:

$$
\begin{aligned}
& \left.L=E_{0}^{X}-t u\left[c_{t} ; g_{t} ; X_{t}\right)\right] \\
& +, \quad b_{i} 1 u_{c ; 0} i E_{0}^{X}{ }_{t=0}^{-t}\left[u_{c ; t}\left(w_{t}\left(1 ; x_{t}\right) ; g_{t}\right) ; u_{x ; t}\left(1+m_{t}\right)\left(1 ; x_{t}\right)\right]^{\#}
\end{aligned}
$$

The first order conditions we find are:

$$
\begin{array}{r}
i u_{c ; t} f_{1 ; x ; t}+u_{x ; t}+, \bigodot_{1 t}=0 \\
i u_{c ; t}+u_{g ; t}+, c_{2 t}=0
\end{array}
$$

where

$$
\begin{aligned}
& \bigodot_{1 t}=u_{c c ; t} f_{1 ; x ; t}\left[f_{1_{i} x ; t}\left(1 ; x_{t}\right) ; \quad g_{t}\right] ; \quad u_{c ; t} f_{1_{i} x l_{i} x ; t}\left(1 ; x_{t}\right) \\
& +u_{c ; t} f_{1 ; x ; t}+u_{x x ; t}\left(1 ; x_{t}\right)\left(1+m_{t}\right) ; u_{x ; t}\left(1+m_{t}\right) \\
& +u_{x ; t} m_{x ; t}\left(1 ; x_{t}\right)
\end{aligned}
$$

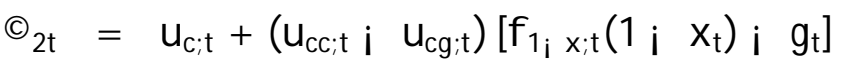

with $\mathrm{m}_{\mathrm{x} ; \mathrm{t}}$ being the derivative of the mark-up with respect to leisure

These are the equations we have to solve, jointly with the implementability constraint, in order to find the optimal paths for the endogenous variables. 
Again these paths can be represented by a time-invariant function of $\mu_{t}$ and :

$$
\left(c_{t} ; x_{t} ; g_{t} ; i t ; p_{t} ; b_{t}\right)=d^{N C}\left(, ; \mu_{t}\right)
$$

\section{$2.4 \quad$ Numerical results}

We are interested in studying the dynamic equilibrium allocations for the models described in the previous section. In both models considered there are two state variables $\left(, ; \mu_{t}\right)$ while the endogenous variables are $\left(c_{t} ; x_{t} ; g_{t} ; i_{t} ; p_{t} ; b_{t}\right)$.

We have to specify functional forms for both, the production function and preferences. We assume a Cobb-Douglas technology showing constant returns to scale:

$$
f\left(\mu_{t} ; 1 ; x_{t} ;{ }_{t}\right)=\mu_{t}\left(1 ; x_{t}\right)^{\circ}{\stackrel{t}{1}{ }^{\circ}}^{\circ} \quad 0<{ }^{\circ}<1
$$

and the following functional form for the preferences:

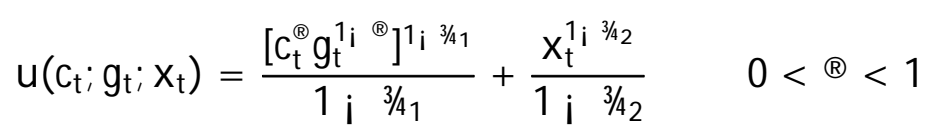

This utility function is additively separable in consumption and leisure. We are considering a composite consumption index which includes both the privately and the publicly provided good. ${ }^{12}$

\footnotetext{
${ }^{12}$ This idea appears in Kormendi (1983), Aschauer (1985) and Christiano and Eichenbaum (1992) where it is assumed that consumption services $\left(c_{t}^{S}\right)$ are related to private $\left(c_{t}\right)$ and public consumption $(\boldsymbol{g})$ as follows:

$$
C_{t}^{s}=C_{t}+R_{g}
$$

However, we want to allow for some complementarity between $c_{t}$ and $g_{t}$ and that is why we assume this relationship between these two variables. The main results are robust to different specifications for this relationship.
} 
The first order conditions are non-linear functions of the endogenous variables. Due to these strong non-linearities there is no way of obtaining closed form solutions to the models. Furthermore, decision rules depend not only on $\mu_{\mathrm{t}}$ but also on the unobservable shadow price, and we have to solve in both economies for comparability purposes. Taking, as given like in Lucas and Stokey, we could study the sign of the derivative of the endogenous variables with respect to the shock. However, comparisons between the equilibrium paths in the competitive and the non-competitive models require solving for this variable. These facts lead to the need for numerical simulations.

In order to find the equilibrium solutions for both models we have to specify values for the parameters appearing in them. The values we have chosen are presented in Table $1 .^{13}$

This parameterization is quite similar to that used in the real business cycle literature. That is the case of the subjective time discount rate $\left(^{-}\right)$, the parameter of the production technology $\left({ }^{\circ}\right)$, and the parameter values for the productivity shock innovation process $(1 / 2$ and $3 / 4)$. The value chosen for the parameter ${ }^{\circledR}$ matches the empirically observed fact that private consumption is about four times larger than public spending in the deterministic version of the model. Finally, while the choice for $3 / 4$ is quite standard, the choice for $3 / \mathbb{2}$ is arbitrary but this does not affect the results.

\footnotetext{
${ }^{13}$ Our aim is to study if imperfections in the labor market justify a different optimal fiscal policy and not so much to match the observed data. That is why we did not calibrate the economy as well as possible to the data.
} 
Table 1: Parameter Values

\begin{tabular}{|c|c|}
\hline \multicolumn{2}{|l|}{ Preferences } \\
\hline- & 0.95 \\
\hline ® & 0.8 \\
\hline $3 / 4$ & 3 \\
\hline $3 / 4$ & 2 \\
\hline \multicolumn{2}{|c|}{ Production Function } \\
\hline$\circ$ & 0.66 \\
\hline \multicolumn{2}{|c|}{ Technology Shock } \\
\hline $1 / 2$ & 0.95 \\
\hline $3 / 4$ & 0.01 \\
\hline
\end{tabular}

We use the following procedure to compute the solution. We start with a given government initial indebtedness $b_{i} 1$ and a realization for the technology shock $f \mu_{t} g_{t=0}^{\top}$. Then, assuming a fixed value for the Lagrange multiplier , associated with the implementability constraint we solve equations (11)-(12) in the competitive case (or (14)-(15) in the non-competitive one). We obtain an allocation $f c_{t} ; x_{t} ; g_{t} g$ that solves the first order conditions for this particular realization of the productivity shock. If we repeat this procedure using $\mathrm{N}$ different realizations of the shock we get the $\mathrm{N}$ equilibrium paths for the endogenous variables given these shock sequences. Next, we average across these $\mathrm{N}$ realizations to approximate the expectation in the right-hand side of the implementability constraint (9). If this average is different from $b_{i}$ we change the proposed, and iterate until the implementability constraint is satisfied. 
We present our results graphically plotting the decision rules $d^{C}(, ; \Phi$ and $d^{N C}(, ; \phi$. Actually, these figures show the correlation between the variables depicted and can be used to study their cyclical properties. Figure 1 shows these plots.

As we can see, consumption is pro-cyclical in both models and it is larger in the neoclassical one. The difference between the models with respect to this variable is larger when the economy is booming, that is, when the productivity shock $\mu_{\mathrm{t}}$ is higher.

Government spending moves with the technological shock. Therefore, we can conclude that there is no stabilization policy with respect to public expenditure. We do not observe a crowding-out effect of private consumption by the public expenditures. On the contrary, both private consumption and public services inherit the autocorrelation properties from the technological shock and show the same behavior over the cycle. In order to analyze properly whether there are stabilization policies we should study not the level of government expenditures, but the public spending-output ratio. The corresponding graph shows that optimality requires this ratio to be fairly constant. Hence, the fiscal policy implemented by the government seeks to stabilize this ratio and public services are not used to offset the impact of recessions over private consumption. These two figures deliver one of the main conclusions of the paper: both the level of government expenditures and the public spending-output ratio are larger in the competitive model than in the non-competitive one. Besides, the slope of the curve depicted is smaller in the model with imperfections in the labor market (1.2 vs 1.4 in the neoclassical model). Therefore, we can conclude that when the government sets the 
fiscal policy optimally, not only the size of the public sector is larger in the neoclassical model but also this government reacts more actively to productivity shocks. This result goes against the conventional belief that keynesian economics $^{14}$ imply that an active stabilization public policy is desirable. ${ }^{15}$ Keynesians recommended that the government should carry out policies of demand so as to stabilize the economy. In fact, using the IS-LM framework to analyze the role of government in economic policy, it can be concluded that the effect of public spending is less important when neoclassical assumptions are made.

Leisure is a pro-cyclical variable. In good times, that is, when the technological shock is high, the labor marginal revenue is also higher and the consumer earns more. The household has to work to get income to buy the consumption good, but it also derives utility from leisure. As a result, when the wage per unit of time worked is high enough, the consumer decides to increase his leisure time. The household works fewer hours in the non-competitive framework, since the union sets higher wages.

The last figures permit us to draw the following conclusions on how the government funds its expenditures. As in the public spending case, the public sector does not use taxes to stabilize the economy. Optimal labor income tax rates should be smaller when the productivity shock is high in order to

\footnotetext{
${ }^{14}$ Modelling "new keynesian" as a deviation from perfect competition agrees with Mankiw and Romer (1991): "A recurrent theme in new Keynesian economics is that deviations from perfect competition may be crucial for understanding economic fluctuactions". However, "new keynesian" means many things in the literature and other authors consider that more requirements are needed to call a model "new keynesian".

15 "The main task should be to prevent large fluctuations by a stable long-term programme" (Keynes, Activities 1940-1946 shaping the Post-War World: Employment and Commodities vol.XXVII)
} 
minimize the distortions introduced by this kind of taxation. In good times it is not worth distorting economic decisions with higher tax rates. The increase in wages makes tax revenues larger even with smaller tax rates. We notice that taxes are always smaller in the non-competitive case. The reason which explains this result is the following: in the model with rigidities the government spends less and, as we will see later, it prefers to finance these expenditures issuing bonds. Due to the existence of a union, the noncompetitive model introduces an additional distortion in the labor market. Consequently, the effect of a tax is even worse in this framework. The government tries to reduce these negative effects setting smaller tax rates. We may think that the government, as the Stackelberg leader in the game, could set a labor-income tax aimed to deal with the advantage the worker has in the labor market. The government would like to subsidize labor in the non-competitive model in order to reach the efficient allocation of this input and increase output. The only taxation instrument available is the distorting labor-income tax rate and these subsidies are not feasible. Therefore, in the non-competitive framework the government sets a positive labor income tax rate, being this tax smaller than that set by the "neoclassical Ramsey planner". As a result, wages are smaller before and after tax in the model without imperfections.

We have also plotted the government debt payments for each realization of the technology shock. ${ }^{16}$ This variable is positive in bad times (when the technological shock is below its mean which is one approximately) and negative when the shock is higher. Therefore, as we could expect given the

\footnotetext{
${ }^{16}$ Appendix A describes how this debt payments have been calculated.
} 
complete market assumption, the government uses debt as a sort of selfinsurance. Besides, we observe superavits (negative primary deficit) in bad times and deficits in good times. This result reverses that found in papers assuming an exogenous government spending, like Lucas and Stokey (1983) or Chari, Christiano and Kehoe (1994) where the smooth optimal tax rate involve running a surplus during boomings and deficits in bad times. In our paper, the planner also aims to smooth distortions over states of nature, but now, the additional degree of freedom in determining the public expenditures, explains the different result.

Finally, the last plot in Figure 1 enables us to conclude that the proportion of public expenses (including the provision of the public good and debt payments) financed with debt ${ }^{17}$ is larger in the non-competitive model. This outcome seems to agree with what is commonly seen as a keynesian policy feature.

In order to gain intuition about our results, we are going to consider the first best solution, that is, the case which assumes that public policy does not distort the agent's economic decisions because expenditures are financed with lump-sum taxes. Table 2 shows the comparisons among the first best solution and those found to the two models studied:

\footnotetext{
${ }^{17}$ The public sector's income inequal to tax revenues $\left(i_{t} \mathbf{W}_{t}\left(1 ; \mathbf{x}_{t}\right)\right.$ ) plus the money he gets selling contingent debt $\left(p_{t}(\mu) b_{t}(\mu) d \mu\right)$. The variable appearing in Figure 9 has been calculated as the fraction of government revenues raised through debt purchases for the states of nature in which the household receives bond payments from the government.
} 
Table 2: Comparisons among models

(means of variables)

\begin{tabular}{|c|ccc|}
\hline & First Best & Competitive & Non-Competitive \\
\hline G/Y & 0.2 & 0.19 & 0.18 \\
$\mathbf{C} / \mathbf{Y}$ & 0.8 & 0.81 & 0.82 \\
$\mathbf{X}_{\mathrm{t}}$ & 57.65 & 61 & 66 \\
\hline
\end{tabular}

The assumption that the government finances its expenditure with lumpsum taxation yields the Pareto-optimal solution. When we include laborincome taxes in the model public policy is going to distort not only the leisure equilibrium allocation but also the consumption one. The competitive model adds this distortion to the first best case and moves the equilibrium solution away from the optimal one. The existence of a union introduces an additional distortion which makes the equilibrium depart from the first best in the same way as the distortion due to the labor-income taxation. The government cannot do much to prevent the union from raising wages but it can reduce the distortion introduced by taxation by diminishing these taxes. As a result, the government in the non-competitive model spends less and finances a larger proportion of its expenditure with debt.

To sum up, the model with imperfect competition in the labor market delivers the same conclusion as the competitive one with respect to the stabilization policy recommendations: using government spending to offset the negative productivity shocks is not optimal. Furthermore, the assumption of the existence of a union with monopoly power in the labor market results in smaller government expenditure. 


\section{The incomplete markets model}

Once we have got the intuition behind the results with the complete markets assumption, we aim to perform the same kind of exercise as before but assuming that the only asset available to the government is risk-free debt. The contingent debt assumption made in the preceding section is useful because it makes equilibria easier to compute. However, relaxing this assumption we can study how debt purchases evolve over the business cycle. The debt pattern observed in the complete markets case is not very interesting. In this model, debt can be represented by a time-invariant function of the productivity shock. That is, the government always purchases the same quantity of bonds contingent on each state of nature. And these debt issues do not depend, for instance, on outstanding debt obligations. We think that more interesting results may be obtained if a different debt structure is considered.

Moreover, we think that the results we have got may be biased by the complete markets assumption. With complete markets for the debt, agents purchase bonds in order to "insure" themselves against any contingency it may occur. Then the role of the government as the economic agent who has to decide a policy aimed to deal with the negative effects of shocks may be smaller. The consumer buys this contingent debt and knows that if a bad shock happens tomorrow the debt payments will be larger. The government does not provide more public goods in bad times because the tax required to finance this expenditure should be too large and it is not worth introducing such a big distortion in the economy. To some extent, this stabilizer role is fulfilled by the non-distorting contingent debt. ${ }^{18}$

\footnotetext{
${ }^{18}$ Lucas and Stokey (1983) note that state contingent debt acts as a shock absorber in
} 
In this section we are going to present two models with the same features as those in section 2 but now assuming that the only debt in this economy is risk-free debt. The theoretical setup is basically the same as the one described in subsection 2.1. Now the consumer's budget constraint is the following:

$$
c_{t}+p_{t}^{b} b_{t}=\left(\begin{array}{ll}
1 & i_{t}
\end{array}\right) w_{t}\left(1 ; x_{t}\right)+b_{t_{1} 1}+p_{t}^{\prime} t
$$

Therefore, the consumer buys today the right to receive $b_{t}$ units of consumption good tomorrow no matter the state of nature. In the incomplete market setup we are going to bound the debt market imposing debt limit constraints, that is,

$$
\underline{M} \cdot b_{t} \cdot \bar{M}
$$

As in the model presented above the consumer maximizes the objective function (3) subject to his budget constraint (16). The first order condition resulting from the derivative with respect to leisure is the same as in the complete markets case, i.e. (10) in the competitive model and (13) in the non-competitive one. Again, the consumer supplies inelastically his land endowment. Finally, the other neccesary condition is:

$$
p_{t}^{b}=-\frac{E_{t}\left[u_{c ; t+1}\right]}{u_{c ; t}}
$$

The firm's problem remains the same as in the complete markets framework. The first order conditions resulting from this problem imply that inverse labor demand of each input equals the corresponding marginal productivity.

these models. 
Again the Ramsey planner sets the fiscal policy that maximizes the consumer's objective function taking into account how the consumer reacts to these policy announcements.

When we assumed complete debt markets we summarized the temporal sequence of government budget constraints, and the first order conditions of the consumer's problem in one equation, i.e. (9). As it is proved in Marcet, Sargent and Seppälä (1996) this does not happen in the incomplete markets setup anymore. Now, the restriction that these equations place on equilibrium allocations is characterized by the following sequence of constraints:

$$
b_{t_{1} 1}=E_{t}{ }_{j=0}^{\lambda}-j \frac{u_{c ; t+j}}{u_{c ; t}}\left[i t+j w_{t+j}\left(1 ; x_{t+j}\right) i \quad g_{t+j}\right] \quad 8 t
$$

In order to solve the Ramsey problem considering this sequence of equations we have adopted the same approach as Marcet, Sargent and Seppälä (1996). We can write the Lagrangian for this problem as

$$
\begin{aligned}
L= & E_{0}{ }_{t=Q}^{X}-t{ }^{n} u\left(c_{t} ; g_{t ;} x_{t}\right)+\grave{A}_{1 t}\left(\bar{M} ; b_{t}\right)+\grave{A}_{2 t}\left(b_{t} ; \underline{M}\right) \\
& +{ }^{1}{ }_{t} 4 b_{t ;} u_{c ; t} i E_{t}{ }_{j=0}{ }^{-j} u_{c ; t+j}\left[i_{t+j} w_{t+j}\left(1 ; x_{t+j}\right) i g_{t+j}\right]^{5}
\end{aligned}
$$

where ${ }^{1}{ }_{t}$ is the time varying Lagrange multiplier associated with the time $t$ implementability constraint, and $\grave{A}_{1 t}$ and $\grave{A}_{2 t}$ are the multipliers associated with the debt constraints.

We can rewrite this expression and get:

$$
L=E_{0}^{X}-t h u\left(c_{t} ; g_{t} ; x_{t}\right) ; \tilde{A}_{t} u_{c ; t}\left[i t w_{t}\left(1 ; x_{t}\right) ; g_{t}\right]
$$




$$
+{ }_{t} u_{c, t} b_{t i 1}+\grave{A}_{1 t}\left(\bar{M} ; b_{t}\right)+\grave{A}_{2 t}\left(b_{t} ; \underline{M}\right)^{0}
$$

where

$$
\tilde{A}_{t}=\tilde{A}_{t_{i} 1}+{ }^{1} t \quad \tilde{A}_{i 1}=0
$$

Now, the optimal paths for the endogenous variables at time $t$ are a time invariant function of three state variables $\left(\tilde{\mathrm{A}}_{\mathrm{t}_{\mathrm{i}}} ; \mathrm{b}_{\mathrm{t}_{i} 1} ; \mu_{\mathrm{t}}\right)$.

If we consider the model without imperfections, the first order conditions of the Ramsey problem can be written as:

$$
\begin{aligned}
& i u_{c i t} f_{1_{i} x ; t}+u_{x ; t}+\tilde{A}_{t^{-}}{ }_{1 t} ;{ }^{1}{ }_{t} u_{c c ; t} b_{p_{i} 1} f_{1_{i} x ; t}=0 \\
& \mathrm{i} u_{c ; t}+u_{g ; t}+\tilde{A}_{t^{-} 2 t} i^{1}{ }_{t}\left(u_{c c ; t} i u_{c g ; t}\right) b_{t_{i} 1}=0 \\
& \grave{A}_{1 t}+\grave{A}_{2 t}+{ }^{-} E_{t}{ }^{h} u_{c t t+1}{ }^{1}{ }_{t+1}^{i}=0
\end{aligned}
$$

where - 1 t and - $2 t$ are the expressions appearing in the first order conditions calculated for the complete markets case.

On the other hand, the first order conditions of the Ramsey problem when it is assumed that the union sets wages are the following:

$$
\begin{aligned}
& i u_{c ; t} f_{1 i x ; t}+u_{x ; t}+\tilde{A}_{t} \odot_{1 t} i{ }^{1}{ }_{t} u_{c c ; t} b_{u_{i} 1} f_{1 i x ; t}=0 \\
& \mathrm{i} u_{c ; t}+u_{g ; t}+\tilde{A}_{t} \Theta_{2 t} i^{1}{ }_{t}\left(u_{c c ; t} i u_{c g ; t}\right) b_{t_{i} 1}=0 \\
& \grave{A}_{1 t}+\grave{A}_{2 t}+{ }^{-} E_{t}{ }^{h} u_{c t t+1}{ }^{1} t+1=0
\end{aligned}
$$

We want to find the optimal paths for the endogenous variables of the model $\left(c_{t} ; x_{t} ; g_{t} ; \iota t ; p_{t} ; b_{t} ; \grave{A}_{1 t} ; \grave{A}_{2 t}\right)$. The state of the economy is given by three 
variables $\left(\mu_{\mathrm{t}} ; \tilde{\mathrm{A}}_{\mathrm{t}_{\mathrm{i}} 1} ; \mathrm{b}_{\mathrm{t}_{\mathrm{i}} 1}\right)$. We are also interested in the transition functions that show how $\tilde{A}_{t}$ and $b_{t_{i} 1}$ depend on the vector of state variables.

As we can see from the equations above, when we assume incomplete markets we cannot get rid of expectations in the first order conditions of the Ramsey problem. So we have to deal with them when solving the model. The method we have used is the parameterized expectations algorithm (PEA) of Marcet (1988). Details about this method and its implementation to find the optimal allocations are described in Appendix B.

We present different ways to analyze the results of the simulations. When we studied the complete markets case we simply plotted the decision rules. The incomplete markets assumption imply decision rules depending on three state variables: the technological shock $\mu_{t}$, the multiplier $\tilde{A}_{t_{i} 1}$ and the outstanding debt at $t, b_{i_{1}}$. As far as we are not able to draw a graph displaying the relation among four variables, decision rules can not be plotted in the incomplete markets case. The graphs in Figure 2 resemble those found in the complete markets case but now, when we plot the productivity shock versus the endogenous variables we are only studying the relation on average between them. Private consumption, public expenses and leisure move with the technology shock while the labor income tax rate is negatively correlated with this variable. There are two new variables that we can study when we include risk-free debt in the model: debt purchases and the excess burden of taxation. In the complete markets setting, we could only compute the debt payments and these payments were positive in bad times and negative during expansions. When incomplete markets are assumed, debt purchases are always positive and are larger when the productivity shock is higher. An- 
other new result is that referred to the deadweight loss of taxation which is measured by the multiplier $\tilde{A}_{t}$. When we assumed that there were complete markets for the contingent debt the deadweight loss of taxation was measured by the time invariant Lagrange multiplier . Now, in the incomplete markets case, this excess burden is going to be time varying. This variable can be interpreted as a sort of shadow price. It indicates the cost of public expenditure due to the use of distorting taxes to fund it. Figure 2 shows that the absolute value of the deadweight loss is larger during expansions. Therefore, the cost of increasing taxes is higher in good times. This seems to be a reasonable explanation for the decreasing pattern observed for the tax rate.

Another way to display the results is to plot the endogenous variables versus the technological shock holding the debt, $b_{t_{i}}$, fixed and setting the multiplier, $\tilde{A}_{t_{i} 1}$, at its mean conditional value on the debt. Figures $3 \mathrm{a}$ and $3 \mathrm{~b}$ show these results. The same conclusions are reached when we use this way to analyze the simulated series. Private consumption, government spending and leisure are positively correlated with output. The government spendingoutput ratio should remain constant over the business cycle. Again, the figure shows that the labor income tax rate is downward sloping. We have displayed these graphs for different values for the debt and the results are the same.

We have also computed the impulse response functions for the decision rules. For the simulated series, we run regressions of the endogenous variables against $f{ }^{\prime}{ }_{i s} g_{s=0}^{L}$, being " the innovation of the technological shock $\mu$. Figure 4 displays the estimated coefficients. This analysis allows us to study the 
effect of an independent shock on future variables. These figures show that an unexpected shock in the technology has a positive effect on private consumption, government spending and leisure. On the other hand, the effect of the shock on the government spending-output ratio is small, permanent and almost constant. This explains the result that optimality implies that this ratio should be constant. As far as the shock " has a zero mean, the effects of the present and past realizations of " on the government spending-output ratio at $\mathrm{t}$ cancel out. Our results also predict a positive response for debt purchases and a negative one for the labor income tax rate.

The different exercises performed to analyze the results of simulations lead to similar conclusions. Besides, these conclusions are the same as those we obtained in the complete markets case. It is not optimal to implement stabilization policies. As in the framework assuming contingent debt and complete markets, the optimal level of government spending should increase as much as output during expansions, that is, the public spending-output ratio should be constant over the cycle. These higher level of expenditure is optimally supported by lower taxes and larger debt issues. The procyclicality of debt is a new result that arises when only risk-free debt is allowed. The government has to decide how much of the larger public spending is financed by debt and how much by taxes. As long as the excess burden of taxation is larger during expansions, the government increases the primary deficit and issues more debt. Moreover, government income has to increase not only because of the larger public provision of the good but also because debt obligations are higher.

The graphs we have just described show the results of simulations for 
the competitive model. The conclusions for the non competitive model are qualitatively the same. As in the complete markets case, we are interested in comparing the results obtained in the models assuming different behavior in the labor market. Due to the special features of the decision rules in the incomplete markets model, we can not use the plots of the technological shock versus the endogenous variables to compare the competitive model and the non competitive one. The reason is that in spite of the fact that we can display the decision rules corresponding to a given realization of the shock, we cannot set the other two state variables at the same level.

We have calculated the mean of the different endogenous variables in both the competitive and the non-competitive model. These values are presented in Table 3:

Table 3: Means of Variables

\begin{tabular}{||l||cc||}
\hline \hline & $\begin{array}{c}\text { Competitive } \\
\text { model }\end{array}$ & $\begin{array}{c}\text { Non-competitive } \\
\text { model }\end{array}$ \\
\hline \hline Private consumption & 8.99 & 8.38 \\
Government spending & 2.12 & 1.86 \\
Leisure & 61.60 & 66.06 \\
G/Y & 0.19 & 0.18 \\
Debt & 1.97 & 3.97 \\
Tax rate & 0.30 & 0.30 \\
Tax revenues & 2.22 & 2.05 \\
A & -0.12 & -0.36 \\
Debt price & 0.95 & 0.95 \\
\hline \hline
\end{tabular}


This analysis allows us to draw the same conclusions as in the complete markets framework. The new distortion introduced in the labor market lead the government to reduce its spending, in levels and as a proportion of output, and to finance its expenses (including also debt payments) mostly with non-distorting debt (65\% in the non competitive model versus $46 \%$ in the competitive one) Again, in the non competitive framework, the worker receives higher wages and devotes more time to leisure. It is important to notice the difference between the values for the Lagrange multiplier $\tilde{A}$ in the steady state. This implies that the excess burden of taxation is much larger in the non-competitive case.

We would also like to study which of the economies reacts more actively to shocks. We will use the impulse response functions. The estimated coefficients allow us to carry out these comparisons. Figure 5 displays these estimates. Both models show similar patterns and slopes for all the endogenous variables. When the technology variable $\mu_{\mathrm{t}}$ is larger than expected the increase in public spending is larger in the competitive model. However, the main differences between the two frameworks come from the variables related to the funding of government expenditures. When we assume that wages are set by the union, a positive unexpected shock in the technology causes optimal debt to increase more and optimal labor income tax rate be smaller than in the competitive case. The government in the non-competitive model takes advantage of the good state of the technology to reduce distortions in the economy. Thus, it increases public expenses and debt issues in such a way that a reduction in distortions through a smaller labor income tax rate is achieved. In this model, welfare considerations make larger increases in 
public expenditures not desirable.

To sum up, the results of the simulations when we assume incomplete markets lead to the same conclusions for labor, taxes and government services. The optimal fiscal response to shocks to the technology should not be what its commonly known as stabilization policies. On the contrary, the government should increase its expenses and decrease labor income tax rates when the economy is booming. As expected, the result for debt purchases is different from that found under complete markets. Now, this debt is always positive and increases with the technology shock. The comparisons between the competitive model and the non-competitive one also draw the same implications. The union introduces a new distortion in the economy and optimality requires a smaller public spending financed. Raising through debt most of government revenues is also optimal in this non-competitive framework.

\section{Concluding Remarks}

This paper studies if imperfections in the labor market justify a different optimal fiscal policy. We find that fiscal policy should not be used to stabilize. Actually, when solving a Ramsey problem we find that optimality requires constant government spending as a proportion of output. Furthermore, against the conventional belief, the optimal size of the government is smaller when we introduce imperfect competition in the basic model.

These results have some implications for economic modelling and policy recommendations. It is often said that Real Business Cycle models do not recommend active public policies because there are no rigidities and Walrasian 
equilibrium applies. This paper studies a model including these imperfections. We find that in spite of the fact that we are making standard assumptions with respect to functional forms, rigidities and solution methods, our conclusions differ from those expected in keynesian models. The interest of this paper is that, contrary to traditional analysis, the proposed framework allows us to do "proper" study under rigidity. We have been precise about agent's preferences, technology and how agents take decisions. Moreover, we have had to be explicit about what causes frictions in our economy and why the public policy may be desirable.

We can only conjecture what could be introduced in the model in order to find optimal stabilization policies. One of the assumptions that may be causing our results is the shock we are considering. This is an aggregate shock to the technology. A bad shock causes output to be small and reduces the resources available in the economy. All agents are affected by the shock in the same way and the scope for the government intervention may be limited. In any event, this paper has shown that the adopted approach is flexible enough to analyze this kind of questions. Studying the features we could introduce in the basic framework in order to get an optimal stabilization policies would be an interesting future research. 


\section{Appendix A}

In this appendix we describe how debt payments are calculated when state contingent debt is assumed.

Substituting recursively in the government budget constraint (8) we get,

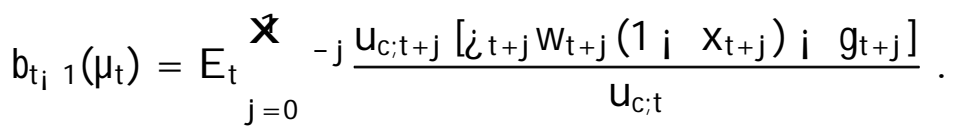

This equation can be rewritten as,

$$
b_{t_{i} 1}\left(\mu_{t}\right)=B_{t+1}+\left[i t w_{t}\left(1 ; x_{t}\right) ; \quad g_{t}\right]
$$

where,

$$
B_{t+1}=E_{t}{ }_{j=1}^{x} \frac{-j}{u_{c ; t+j}\left[i_{t+j} w_{t+j}\left(1 ; x_{t+j}\right) i g_{t+j}\right]} .
$$

For simulated series of the endogenous variables, we have calculated a new series $f B_{t+1} g_{t=0}^{5 ; 000}$ setting $B_{5 ; 000}$ at its value in the steady state. We have run OLS regressions of $B_{t+1}$ on a polynomial function $P\left({ }^{-} ; \mu_{t}\right)$. We call the resulting estimates ${ }^{b}$.

For the series presented in section 2, we have calculated the following expression to approximate $\mathrm{b}\left(\mu_{\mathrm{t}}\right)$,

$$
\mathrm{b}\left(\mu_{\mathrm{t}}\right)=\mathrm{P}\left(\mathrm{b}_{;}, \mu_{\mathrm{t}}\right)+\left[i_{\mathrm{t}} \mathrm{w}_{\mathrm{t}}\left(1 ; \mathrm{x}_{\mathrm{t}}\right) \mathrm{i} g_{\mathrm{t}}\right]
$$

\section{Appendix B}

This appendix describes the method we have used to solve the model when incomplete markets are assumed. In order to find the optimal allocations 
for the endogenous variables, $\left(c_{t} ; x_{t} ; g_{t} ; b_{t} ; \tilde{A}_{t} ;{ }^{1} ; \grave{A}_{1 t} ; \grave{A}_{2 t}\right)$, we have to solve a system of equations. In the competitive model, these equations are the following:

$$
\begin{aligned}
& i u_{c ; t}{ }^{\circ} \mu_{t}\left(1 ; x_{t}\right)^{\circ} i^{1}+u_{x ; t}+\tilde{A}_{t^{-}} 1 t i^{1}{ }_{t} u_{c c ; t} b_{t i 1}{ }^{\circ} \mu_{t}\left(1 ; x_{t}\right)^{\circ} i 1=0 \\
& i u_{c ; t}+u_{g ; t}+\tilde{A}_{t^{-}} 2 t i^{1}{ }_{t}\left(u_{c c ; t} i \quad u_{c g ; t}\right) b_{t_{i} 1}=0 \\
& E_{t}{ }^{h} u_{c ; t+1} \tilde{A}_{t+1}^{i}=\frac{1}{=}\left(\grave{A}_{1 t} i \grave{A}_{2 t}\right)+\tilde{A}_{t} E_{t}\left[u_{c ; t+1}\right] \\
& c_{t}+g_{t}=\mu_{t}\left(1 ; x_{t}\right)^{\circ} \\
& \tilde{A}_{t}=\tilde{A}_{t_{i} 1}+{ }^{1}{ }_{t} \\
& b_{t_{i} 1}=i_{t} w_{t}\left(1 ; x_{t}\right) i g_{t}+{ }^{-} b_{t} \frac{E_{t}\left[u_{c ; t+1}\right]}{u_{c ; t}} \\
& \grave{A}_{1 ; t}\left(\bar{M} ; \quad b_{t}\right)=\grave{A}_{2 ; t}\left(b_{t} ; \underline{M}\right)=0 \\
& \left(\overline{\mathrm{M}} \text {; } b_{t}\right) ;\left(b_{t} \text { i } \underline{M}\right), 0 \quad \grave{A}_{1 ; t} ; \grave{A}_{2 ; t} \cdot 0
\end{aligned}
$$

with

$$
\begin{aligned}
& i_{t}=1 ; \frac{u_{x ; t}}{w_{t} u_{c ; t}} \\
& \text { - } 1 \mathrm{t}=\mathrm{u}_{\mathrm{cc} ; \mathrm{t}} \mu_{\mathrm{t}}{ }^{\circ}\left(1 ; \mathrm{x}_{\mathrm{t}}\right)^{\circ} \mathrm{i}^{1}\left({ }^{\circ} \mu_{\mathrm{t}}\left(1 ; \mathrm{x}_{\mathrm{t}}\right)^{\circ} \mathrm{i} \mathrm{g}_{\mathrm{t}}\right)+\mathrm{u}_{\mathrm{c} ; \mathrm{t}}{ }^{\circ 2} \mu_{\mathrm{t}}\left(1 ; \mathrm{x}_{\mathrm{t}}\right)^{\circ}{ }^{\mathrm{i} 1} \\
& +u_{x x ; t}\left(1 ; x_{t}\right) \text { i } u_{x ; t} \\
& -2 t=u_{c ; t}+\left(u_{c c ; t} ; \quad u_{c g ; t}\right)\left({ }^{\circ} \mu_{t}\left(\begin{array}{lll}
1 & x_{t}
\end{array}\right)^{\circ} i \quad g_{t}\right)
\end{aligned}
$$

This system of equations is quite similar to that we have to solve in the non competitive model. In this case the equations are:

$$
i u_{c ; t}{ }^{\circ} \mu_{t}\left(1 ; x_{t}\right)^{\circ} i^{1}+u_{x ; t}+\tilde{A}_{t} \bigodot_{1 t} i^{1}{ }_{t}^{\circ} u_{c c ; t} b_{t i 1}{ }^{\circ} \mu_{t}\left(1 ; x_{t}\right)^{\circ}{ }^{0}=0
$$




$$
\begin{aligned}
& { }_{h} u_{c ; t}+u_{g ; t}+\tilde{A}_{t} C_{2 t} i^{1}{ }_{t}{ }^{\circ}\left(u_{c c ; t} i u_{c g ; t}\right) b_{t i 1}=0 \\
& E_{t}{ }^{h} u_{c ; t+1} \tilde{A}_{t+1}^{i}=\frac{1}{o^{-}}\left(\grave{A}_{1 t} i \grave{A}_{2 t}\right)+\tilde{A}_{t} E_{t}\left[u_{c ; t+1}\right] \\
& c_{t}+g_{t}=\mu_{t}\left(1 ; x_{t}\right)^{\circ} \\
& \tilde{\mathrm{A}}_{\mathrm{t}}=\tilde{\mathrm{A}}_{\mathrm{t}_{\mathrm{i}} 1}+{ }^{1}{ }_{\mathrm{t}} \\
& b_{t_{i} 1}=i_{t} w_{t}\left(1 ; x_{t}\right) ; g_{t}+{ }^{-} b_{t} \frac{E_{t}\left[u_{c ; t+1}\right]}{u_{c ; t}} \\
& \grave{A}_{1 ; t}\left(\bar{M} ; \quad b_{t}\right)=\grave{A}_{2 ; t}\left(b_{t} ; \underline{M}\right)=0 \\
& \left(\bar{M} ; \quad b_{t}\right) ;\left(b_{t} ; \underline{M}\right), 0 \quad \grave{A}_{1 ; t} ; \grave{A}_{2 ; t} \cdot 0
\end{aligned}
$$

with

$$
\begin{aligned}
& i_{t}=1 i \frac{u_{x ; t}}{{ }^{o} w_{t} u_{c ; t}} \\
& C_{1 t}=u_{c c ; t} \mu_{t}{ }^{\circ 2}\left(1 ; x_{t}\right)^{\circ}{ }^{1}\left(^{\circ} \mu_{t}\left(1 ; x_{t}\right)^{\circ} i \quad g_{t}\right)+u_{c ; t}{ }^{\circ 3} \mu_{t}\left(1 ; x_{t}\right)^{\circ} i^{1} \\
& +u_{x x ; t}\left(1 ; x_{t}\right) \text { i } u_{x ; t} \\
& C_{2 t}=u_{c ; t}{ }^{0}+{ }^{\circ}\left(u_{c c ; t} i \quad u_{c g ; t}\right)\left({ }^{\circ} \mu_{t}\left(1 ; x_{t}\right)^{\circ} i g_{t}\right)
\end{aligned}
$$

We have used the parameterized expectations approach (PEA) for solving these systems. This method replaces the conditional expectation in these equations with an approximating function depending on the state variables and a set of parameters. Then, the equilibrium allocations are simulated using this function in place of the conditional expectations. An iterative procedure leads to a parameterization of the expectations that its consistent with the series it generates. More details about this method can be found in Marcet (1988), Den Haan and Marcet (1990) and Marcet and Marshall (1994).

In this paper we have to parameterize two expectations $E_{t}\left[u_{c ; t+1}\right]$ and 
$E_{t}{ }^{h} u_{c ; t+1} \tilde{A}_{t+1}$, and the vector of state variables is $s_{t}=\left(\mu_{t} ; \tilde{A}_{t i 1} ; b_{t i 1}\right)$. We have replaced these expectations with the functions ' ${ }^{1}\left( \pm^{1} ; s_{t}\right)$ and ' $2\left( \pm^{2} ; s_{t}\right)$ respectively, where:

$$
\begin{aligned}
& { }^{1}\left( \pm^{1} ; s_{t}\right)=\exp \left(P_{n}^{1}\left(s_{t}\right)\right) \\
& { }^{2}\left( \pm^{2} ; s_{t}\right)=P_{n^{0}}^{2}\left(s_{t}\right)
\end{aligned}
$$

and where $P_{n}^{1}$ and $P_{n^{0}}^{2}$ are polynomials of degree $n$ and $n^{0}$ respectively and $\Psi^{1}$ and $\underline{\Psi}^{2}$ are the coefficients in these polynomials ${ }^{19}$. We can distinguish different steps followed to find the solution of PEA:

2 Step 1: Substitute the conditional expectations in the system of equations with the functions ' ${ }^{1}\left( \pm^{1} ; s_{t}\right)$ and ' ${ }^{2}\left( \pm^{2} ; s_{t}\right)$ assuming a given initial value \pm for $\pm^{1}$ and $\pm^{2}$.

2 Step 2: Create a long series for the technological shock $\mu_{\mathrm{t}}$ and solve for the endogenous variables for every period. We call the series we get $f z_{t}( \pm) g$.

2 Step 3: Calculate the expressions inside the conditional expectations for $f z_{t}\left( \pm_{0}\right) g$ and run a non-linear regression of these expressions on the functions ${ }^{\prime}{ }^{1}\left(: ; S_{t}\right)$. We call the resulting coefficients $S\left( \pm_{0}\right)$

2 Step 4: Update $\pm_{0}$ by: $\pm_{1}=\left(1 ;{ }^{\prime}\right) \pm_{0}+{ }^{\prime} S\left( \pm_{0}\right)$ with $2(0 ; 1]$ and iterate the procedure until a fixed point is found, that is, $\Psi_{\sharp}=S\left(\Psi_{\sharp}\right)$.

\footnotetext{
${ }^{19}$ We have chosen different functions for $E_{t}\left[u_{c ; t+1}\right]$ and $E_{t}{ }^{f} u_{c ; t+1} \tilde{A}_{t+1}{ }^{b}$ because the first expectation is always positive and the second one can be postive or negative.
} 
The algorithm has been implemented in GAUSS. We have computed the solutions using 10,000 observations. In order to choose the proper degree for the polynomials we have performed the accuracy tests proposed in Den Haan and Marcet (1989). 


\section{References}

[1] Aschauer, D. (1985): "Fiscal Policy and Aggregate Demand", American Economic Review, vol. 75, pp. 117-27.

[2] Barro, R. (1979): "On the Determination of Public Debt", J ournal of Political Economy, vol. 87, pp. 940-971.

[3] Blanchard, O. (1997): Macroeconomics. Prentice Hall.

[4] Chari, V.V., L. Christiano and P. Kehoe (1994): "Optimal Fiscal policy in a Business Cycle Model", J ournal of P olitical E conomy, vol. 102, pp. 617-652.

[5] Chari, V.V., L. Christiano and P. Kehoe (1996): "Policy Analysis in Bussines Cycle Models", in Frontiers of Bussines Cycle Research, ch. 12, ed. by T. Cooley and E. Prescott. Princeton University Press: Princeton. New Jersey.

[6] Chari, V.V. and P. Kehoe (1998): "Optimal Fiscal and Monetary Policy" Federal Reserve Bank of Minneapolis. Research Department Staff Report 251.

[7] Christiano, L. and M. Eichenbaum (1992): "Current Real-BussinessCycle Theories and Aggregate Labor-Market Fluctuations", American Economic Review, vol. 82, n. 3, pp. 431-450.

[8] Den Haan, W. J. and A. Marcet (1989): "Accuracy in Simulations", unpublished manuscript, Carnegie Mellon University, Graduate School of Industrial Administration. 
[9] Den Haan, W. J. and A. Marcet (1990): "Solving the Stochastic Growth Model by Parameterizing Expectations", J ournal of Business and Economic Statistics, vol. 8, pp. 31-34.

[10] Den Haan, W. J. and A. Marcet (1994): "Accuracy in Simulations", Review of Economic Studies, vol. 61, pp. 3-17.

[11] Jones, L., R. Manuelli and P. Rossi (1993): "Optimal Taxation in Models of Endogenous Growth", J ournal of Political Economy, vol. 101, pp. 485-517.

[12] King R. (1993): "Will the New Keynesian Macroeconomics Resurrect the IS-LM Model?", J ournal of E conomic Prespectives, vol. 7, n. 1, pp. $67-82$.

[13] Kormendi, R. (1983): "Government Debt, Government Spending and Private Sector Behavior", American Economic Review, vol.73, pp. 9941010.

[14] Kydland, F. and E. Prescott (1980): "Dynamic Optimal Taxation, Rational Expectations and Optimal Control", J ournal of Economic Dynamics and Control, vol. 2, pp. 79-91.

[15] Lucas, R. and N. Stokey (1983): "Optimal Fiscal and Monetary Policy in an Economy without Capital", J ournal of M onetary E conomics, vol. 12, pp. 55-93

[16] Mankiw, G. and D. Romer (1991): "Introduction", in New K eynesian E conomics vol.1, Imperfect Competition and Sticky Prices, ch.1, ed. by G. Mankiw and D. Romer. Cambridge: MIT Press. 
[17] Mankiw, G. (1990): "A Quick Refresher Course in Macroeconomics", J ournal of Economic Literature, vol. 28, pp. 1645-60.

[18] Marcet, A. (1988): "Solving Non-Linear Stochastic Models by Parameterizing Expectations", Carnegie Mellon University, Working Paper.

[19] Marcet, A. and D. Marshall (1994): "Solving Nonlinear Rational Expectations Models by Parameterized Expectations: Convergence to Stationary Solutions", Universitat Pompeu Fabra: Economics Working Paper 76.

[20] Marcet, A., T. Sargent and J. Seppälä (1996): “Optimal Taxation without State-Contingent Debt". Mimeo.

[21] Rojas, G. (1993): "Optimal Taxation in a Stochastic Growth Model with Public Capital: Crowding-in Effects and Stabilization Policy", Universitat Pompeu Fabra: Economics Working Paper 62.

[22] Romer, D. (1993): "The New Keynesian Synthesis", J ournal of Economic Prespectives, vol. 7 , n. 1, pp. 5-22.

[23] Zhu, X. (1992): "Optimal Fiscal Policy in a Stochastic Growth Model", J ournal of Economic Theory, vol. 58, pp. 250-289. 
Figure 1: Technological shock vs endogenous variables (Complete markets)
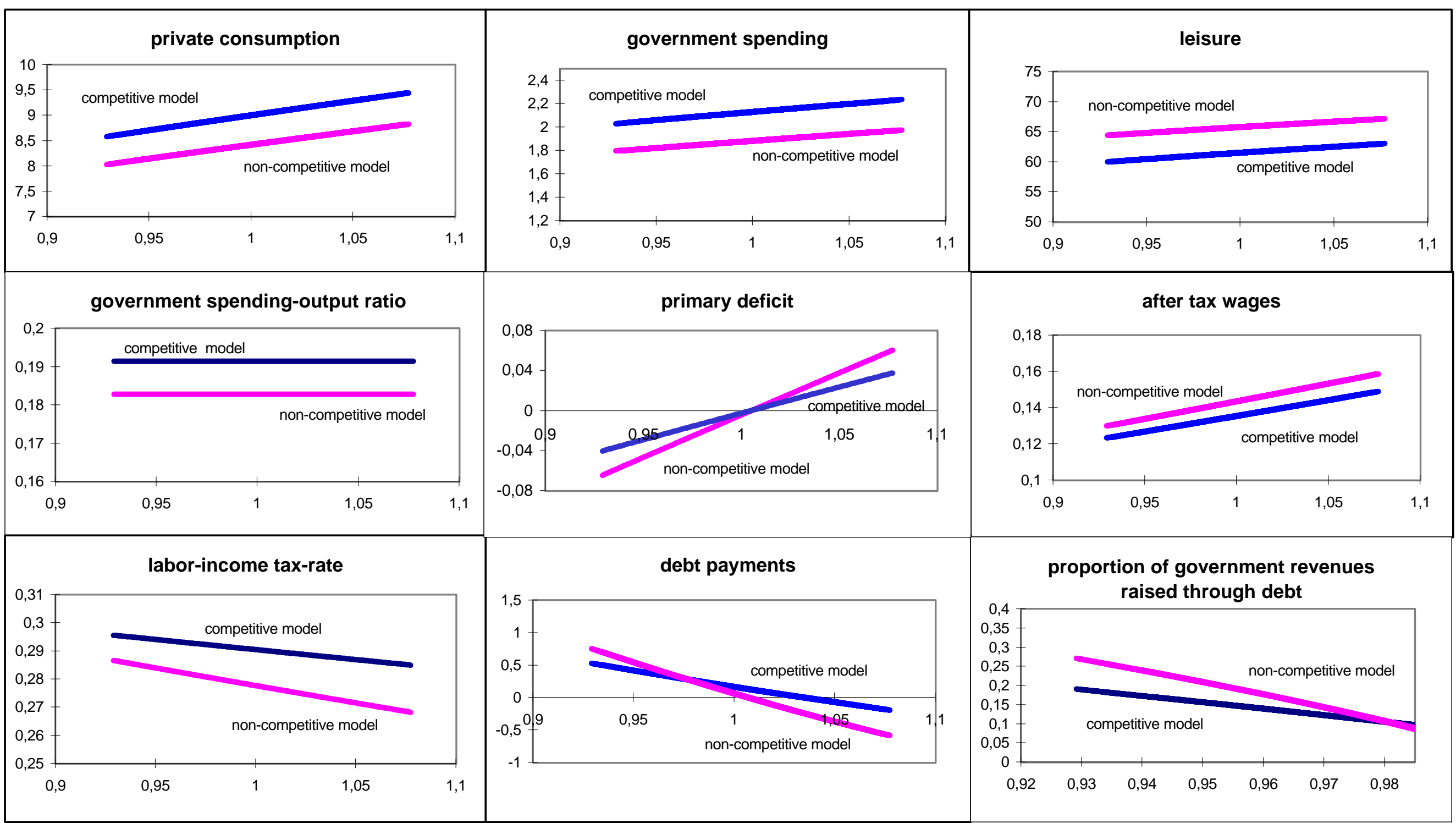
Figure 2: Technological shock vs endogenous variables (Incomplete markets)

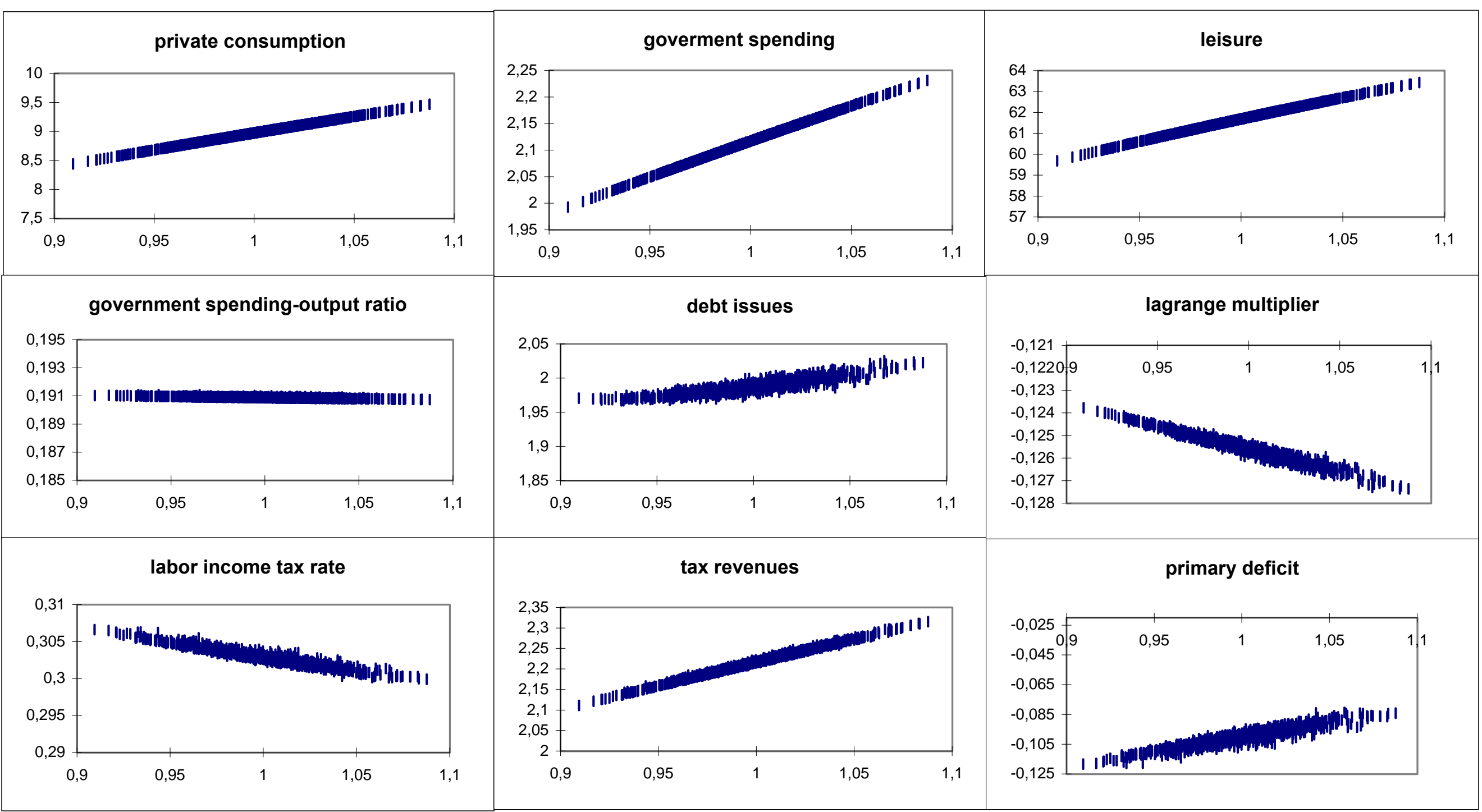


Figure 3a: Technological shock vs endogenous variables holding debt obligations and the lagrange multiplier fixed $b=1.95$ (Incomplete markets)

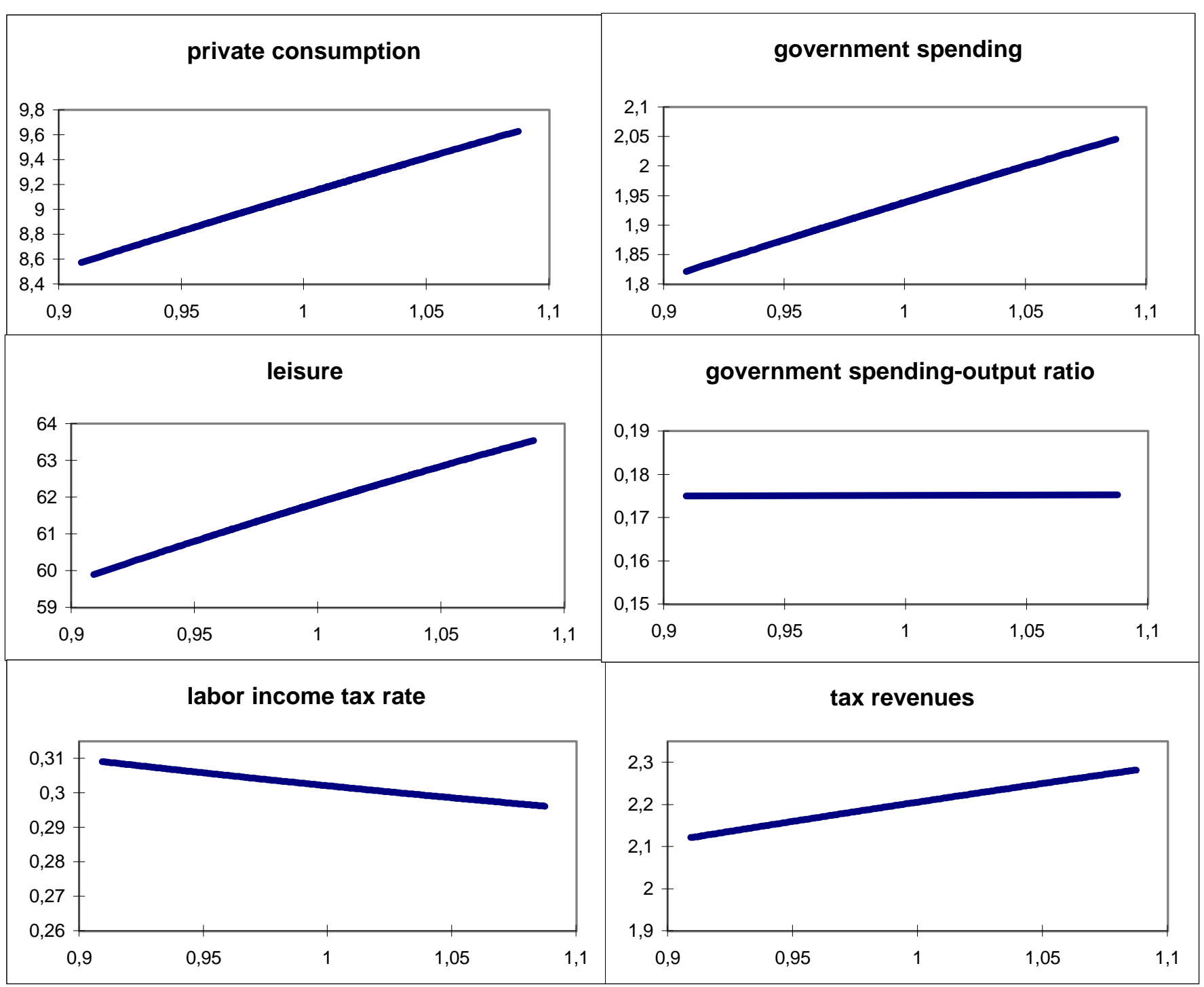


Figure 3b: Technological shock vs endogenous variables holding debt obligations and the lagrange multiplier fixed $b=2.2$ (Incomplete markets)

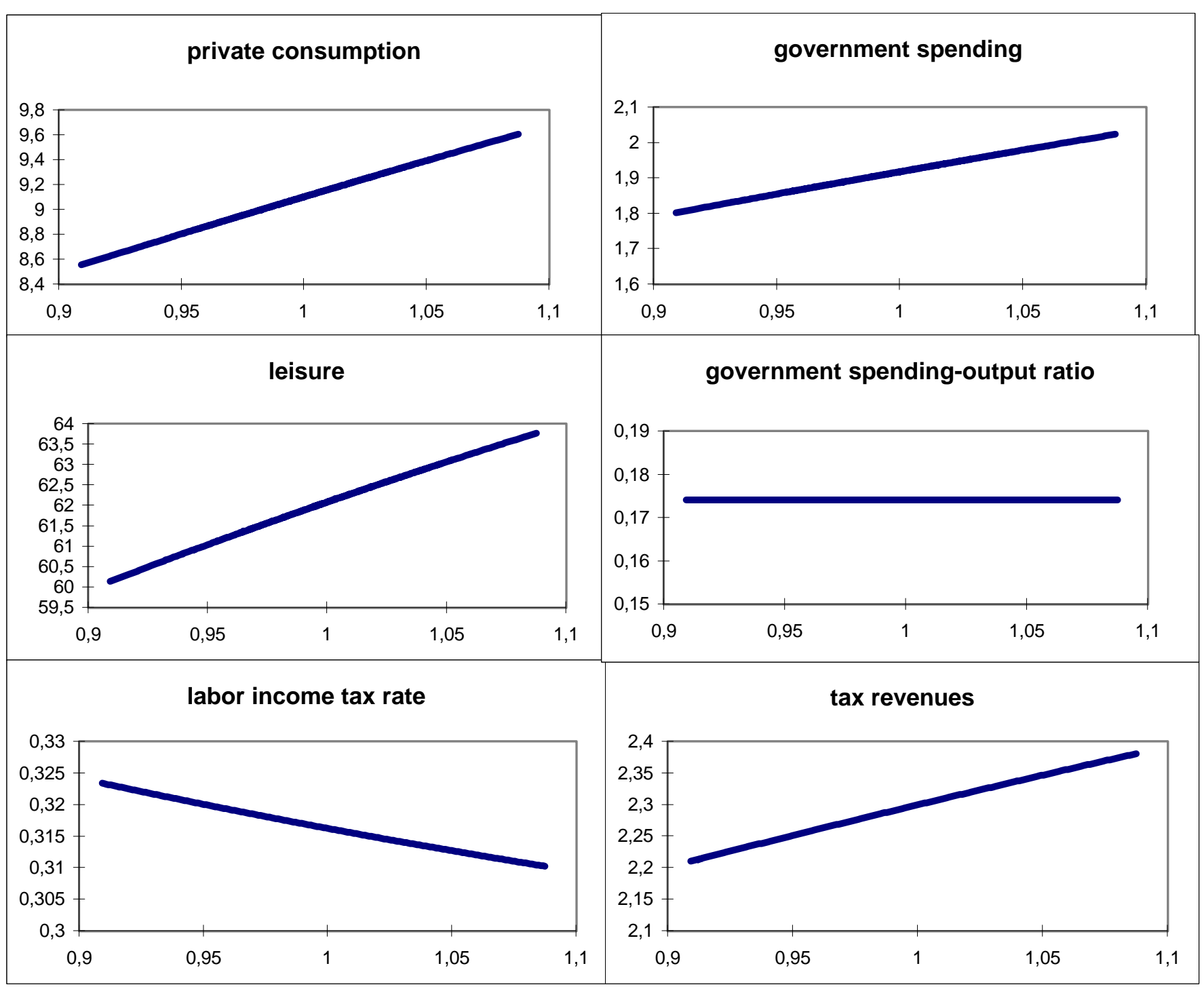


Figure 4: Impulse response functions (Incomplete markets)

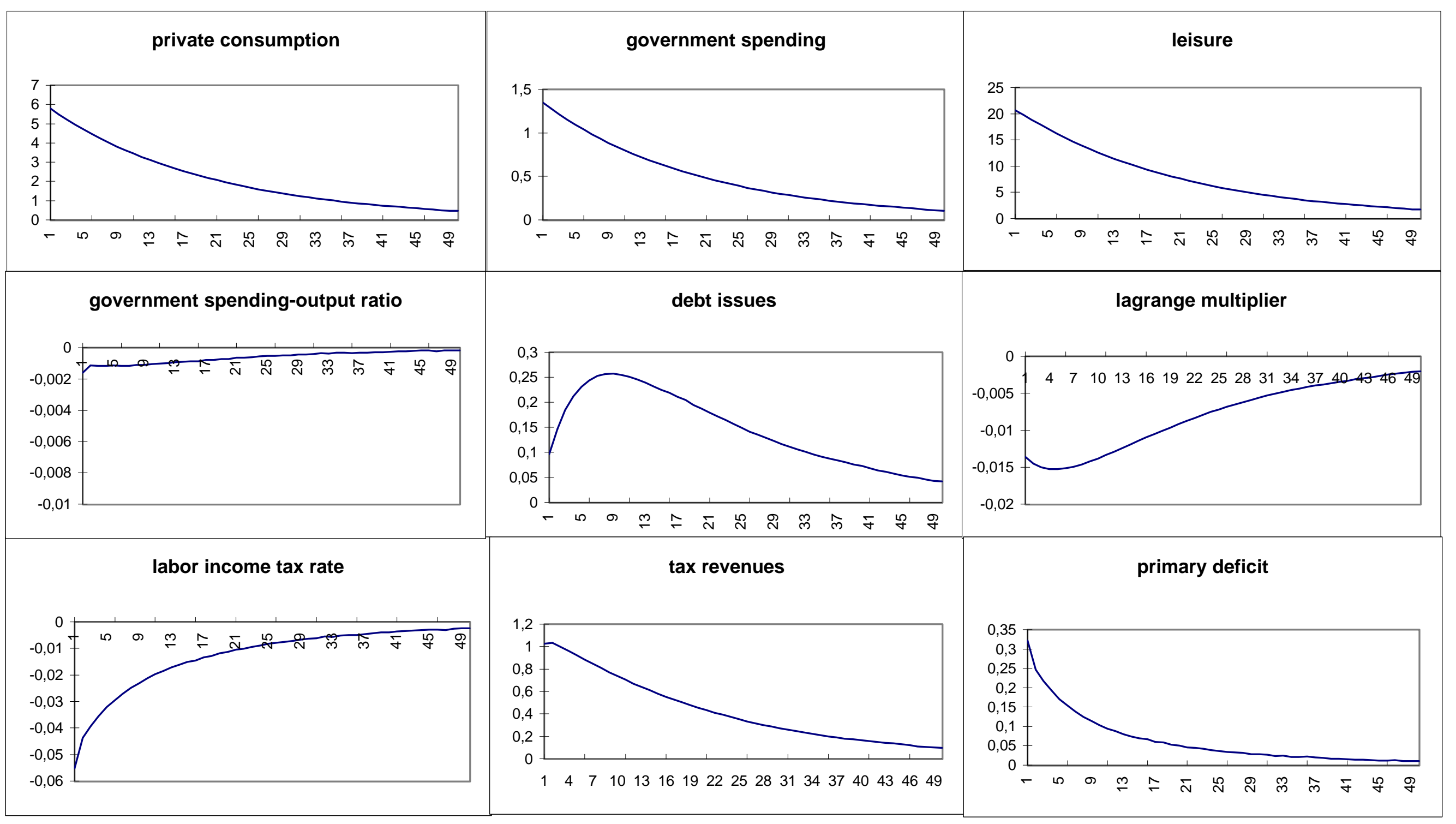


Figure 5: Impulse response functions. Comparison between models (Incomplete markets)

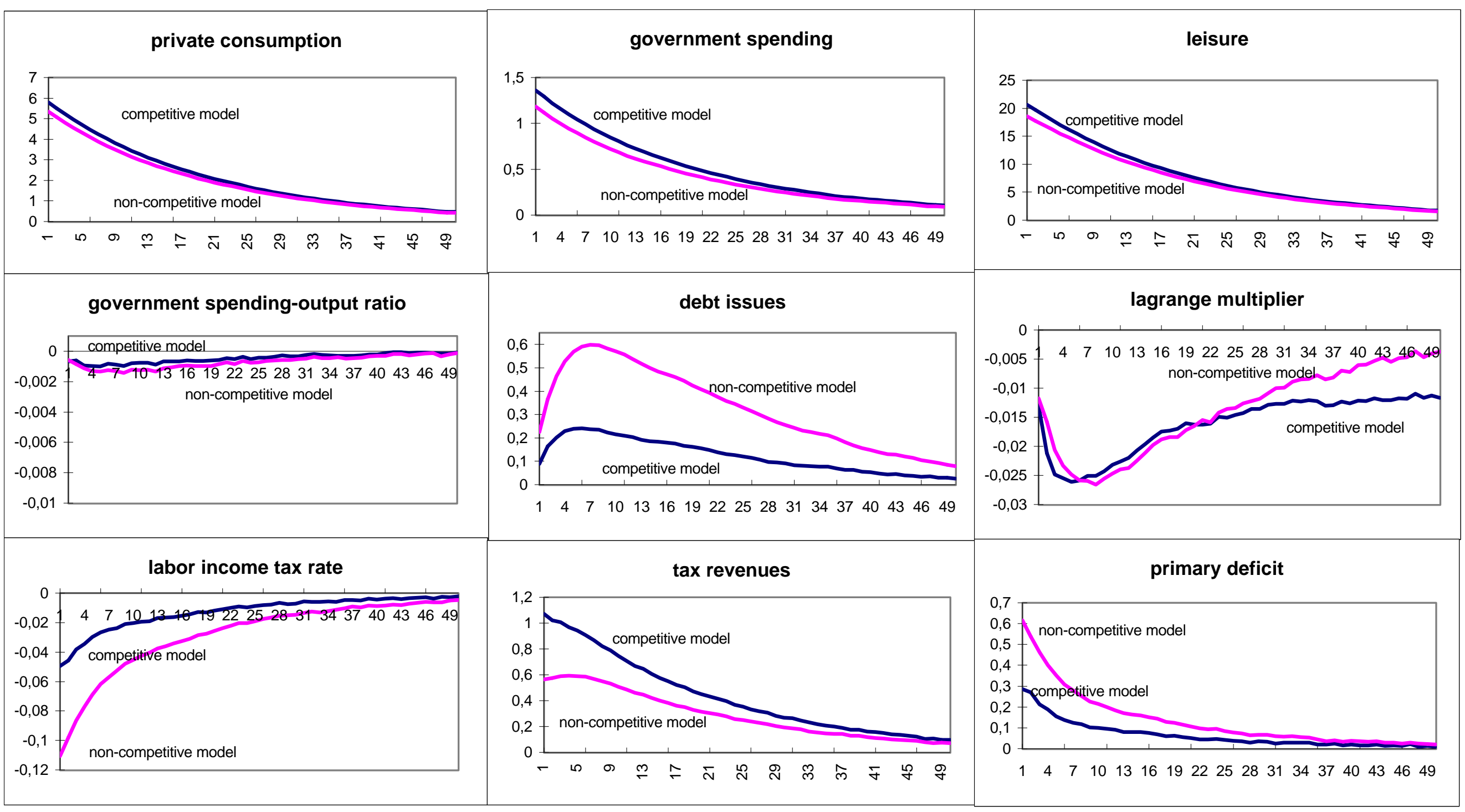

